\title{
Analisis Torsi dan Efisiensi pada Motor Induksi Tiga Fasa Rotor Sangkar
}

\author{
Winarso, Dian Nova Kusuma Hardani
}

Program Studi Teknik Elektro, Universitas Muhammadiyah Purwokerto

\begin{tabular}{l} 
Informasi Ma \\
\hline Dikirim, 03 Ag \\
Direvisi, 03 Ok \\
Diterima, 09 O \\
\\
\hline Kata Kunci: \\
Motor induksi \\
Slip \\
Tegangan \\
Torsi \\
Efisiensi
\end{tabular}

\section{Keyword:}

Induction motor

Slip

Voltage

Torque

Efficiency

\begin{abstract}
INTISARI
Motor induksi merupakan mesin listrik yang banyak digunakan sebagai penggerak misalnya motor sebagai penggerak belt konveyer untuk industry, pompa air, penggerak alat-alat perkakas dan penggerak peralatan rumah tangga. Motor induksi yang sudah digunakan pasti akan mengalami penurunan torsi dan efisiensi karena penurunan kemampuan nilai material. Penelitian ini bertujuan untuk menganalisis besarnya torsi dan efisiensi motor induksi yang sedang dioperasikan. Motor induksi yang sedang digunakan harus di analisis apakah masih efisien atau tidak, tetapi tidak mungkin melepas motor tersebut karena sedang aktif melayani beban. Dengan mengukur parameter motor induksi tanpa harus melepas motor dari beban maka dapat diketahui torsi dan efisiensi motor tersebut. Pada pengujian motor tanpa beban, uji beban penuh dan uji berbeban didapatkan nilai impedansi belitan stator,impedansi belitan rotor dan slip motor. Dari nilai impedansi dan slip dapat diketahui daya input ke stator, daya mekanik rotor, torsi dan efisiensi. Pada pengujian motor induksi dalam keadaan berbeban dengan tegangan kerja 375 volt di dapatkan daya input 2565 watt dengan kerugian pada kumparan stator dan rotor sebesar 743 watt, daya mekanik yang dikeluarkan oleh motor induksi adalah sebesar 1823 watt, torsi yang dihasilkan rotor sebesar $14 \mathrm{Nm}$ dan efisiensi motor sebesar $71,07 \%$.
\end{abstract}

\begin{abstract}
This research is a design of a torque measurement system and efficiency of the three-phase active induction motor is used. Induction motors are electric machines that are widely used as drivers such as motors as conveyor belt drives for the industry, water pumps, as drivers of tool tools and as drivers of home appliances. The induction motors that have been used will inevitably decrease the torque and efficiency due to the decrease in the ability of the material value. This study aims to analyze the amount of torque and efficiency of the induction motor that is being operated. The induction motor that is being used must be analyzed whether it is efficient or not, but it is not possible to remove the motor because it is actively serving the load. By measuring the induction motor parameters without having to remove the motor from the load it can be known the torque and efficiency of the motor. In non-load motor testing, full load test and load test obtained impedance wind value stator, impedance winding rotor and slip motor. From the impedance and slip values can be known input power to the stator, rotor mechanical power, torque, and efficiency. In induction motor testing in a loaded state with a working voltage of 375 volts in getting 2565 watts input power with losses on the stator and rotor coil of 743 watts, the mechanical power released by the induction motor is 1823 watts, torque generated rotor of $14 \mathrm{Nm}$ and efficiency motorcycle equal to $71.07 \%$.
\end{abstract}

\section{Korespondensi Penulis:}

Winarso

Program Studi Teknik Elektro

Universitas Muhammadiyah Purwokerto

Jl Raya Dukuhwaluh Purwokerto

Email: ewinarso@gmail.com 


\section{PENDAHULUAN}

Energi listrik pada motor induksi akan di konversi menjadi energi berguna berupa torsi putar dan menjadi energi terbuang, misalnya kerugian pada belitan, kerugian bantalan dan kerugian celah udara. Energi listrik diperoleh dari energi primer seperti energi fosil, gas, angin, air dan lain-lain. Energi listrik semakin hari akan semakin mahal karena pengaruh dari mahalnya energi primer. Upaya untuk mengurangi konsumsi energy listrik dimulai dengan beban utama yaitu motor induksi [1]. Untuk itu energi listrik yang, masuk ke dalam motor induksi harus dimanfaatkan secara maksimal untuk menjadi torsi putar. Efisiensi merupakan perbandingan antara energi berguna dengan energi masuk, sehingga harapannya motor induksi mempunyai efisiensi yang tinggi agar dapat mengubah energi listrik menjadi torsi putar yang besar. El-ibiary (2003) menjelaskan hasil penggunaan metode yang sangat murah dan akurat dalam menentukan efisiensi motor tanpa perlu menghilangkan penggunaan motor dan tanpa pengukuran daya keluaran atau torsinya [2]. Hasil pengujian menunjukkan bahwa metode yang digunakan mempunyai tingkat akurasi lebih dari 99\%. Karena tingkat akurasi yang tinggi dimungkinkan untuk mengukur potensi penghematan yang besar.

Mantila (2008) mencoba untuk menunjukkan hasil yang berbeda antar standar pengukuran efisiensi [3]. Standar yang digunakan IEEE 112, IEC 60034-2, dan JEC-37. Di dalam studi tersebut dijelaskan langkah-langkah untuk memperkirakan efisiensi di lokasi kerja dan menyatakan perbedaan efisiensi pada motor.

Penelitian yang dilakukan oleh Suyamto pada tahun 2009 adalah menganalisis besaran daya dan torsi pada motor induksi. Penelitian dilakukan terhadap motor induksi 3 fasa 0,1 kW, tegangan : $380 \mathrm{~V}, 0,35 \mathrm{~mA}, 50 \mathrm{~Hz}$, 2800 rpm menggunakan Magnetic Powder Brake UAF-5W sebagai simulator beban mekanik. Dari percobaan, perhitungan dan analisis diketahui bahwa untuk pembebanan sebesar $300 \mathrm{~mA}$ atau 85,7 \% dari beban penuh diperlukan daya.masuk ke motor 169,8 watt. Sedangkan rugi daya pada saat tanpa beban 77,9 watt, rugi daya lilitan stator 22,77 watt, rugi daya lilitan rotor 1,72 watt,. Daya keluar motor bersih sama dengan daya keluar motor kotor sebesar 67,4 watt, dengan torsi dan putaran pada poros motor masing-masing adalah 0,23 N-m dan $2790 \mathrm{rpm}$ [4].

Tahun 2011, sebuah penelitian dilakukan untuk mengetahui efisiensi motor induksi yang sedang digunakan, dimana dalam penelitian ini dilakukan metode pengukuran efisiensi motor induksi sampai dengan $97 \%$ tanpa melepas motor dengan beban dan tanpa mengukur daya mekanik motor atau torsi,sehingga tidak mengganggu proses produksi. [5].

Tahun 2016, sebuah penelitian dilakukan dengan menguji pengaruh torsi beban terhadap kinerja motor induksi tiga fasa dimanabesarnya torsi mekanik akan berdampak pada besarnya torsi induktif sehingga akan berpengaruh pula terhadap besar slip, semakin besar arus masuk, semakin besar arus rotor, semakin besar daya mekanik, semakin besar efisiensi.Bila kondisi ini terus berlangsung, maka akan dapat memperpendek umur motor, Karena inti dan kumparan motor menjadi panas dan akan merusak isolasi kumparan motor sehingga motor cepat rusak. [6].

Pada tahun 2017, dilakukan penelitian kinerja dan parameter motor induksi satu fasa yaitu dengan menguji motor induksi satu fasa tanpa beban dan dengan beban penuh pada tegangan $75 \mathrm{~V}$ sampai tegangan $220 \mathrm{~V}$, dimana di dapatkan parameter impedansi inti motor induksi sebesar 298,7 + J 518,2 ohm serta resistansi dan reaktansi ekuivalen sebesar 126,5 ohm dan 238,1 ohm [7].

Motor induksi adalah salah satu konverter energi listrik ke mekanik yang handal, murah, kokoh kontruksinya dan mjudah perawatannya, sehingga efisiensi motor induksi yang aktif di operasikan harus diketahui nilainya dan dapat di pertahankan guna meningkatkan pelayanan motor induksi dengan murah dan handal..

\section{METODOLOGI PENELITIAN}

Penelitian ini dimulai dengan mempelajari beberapa jurnal maupun naskah publikasi yang berkaitan dengan topik penelitian. Identifikasi masalah yang diangkat pada penelitian ini dilaksanakan saat referensi yang dibutuhkan dianggap telah mencukupi. Setelah identifikasi masalah, proses selanjutnya adalah pengambilan data. Data diambil melalui pengukuran parameter motor induksi dan pengujian motor induksi saat tidak berbeban dan beban penuh. Setelah data diperoleh, tahapan selanjutnya adalah tahap pengolahan data guna mendapatkan besaran-besaran listrik motor induksi seperti nilai impedansi belitan stator dan impedansi belitan rotor. Dengan mengetahui nilai impedansi motor induksi dan slip motor maka dapat menghitung kerugian daya pada belitan stator dan belitan rotor dan pada akhirnya dapat mengetahui nilai daya input rotor dan daya keluaran rotor. Tahap berikutnya adalah menghitung besarnya torsi dan efisiensi dari motor induksi. Setelah sistem dievaluasi, dilakukan dokumentasi lengkap dengan analisis yang diperoleh. Tahap akhir yang dilakukan adalah penyusunan laporan. Lebih jelasnya dapat dilihat pada Gambar 1. 


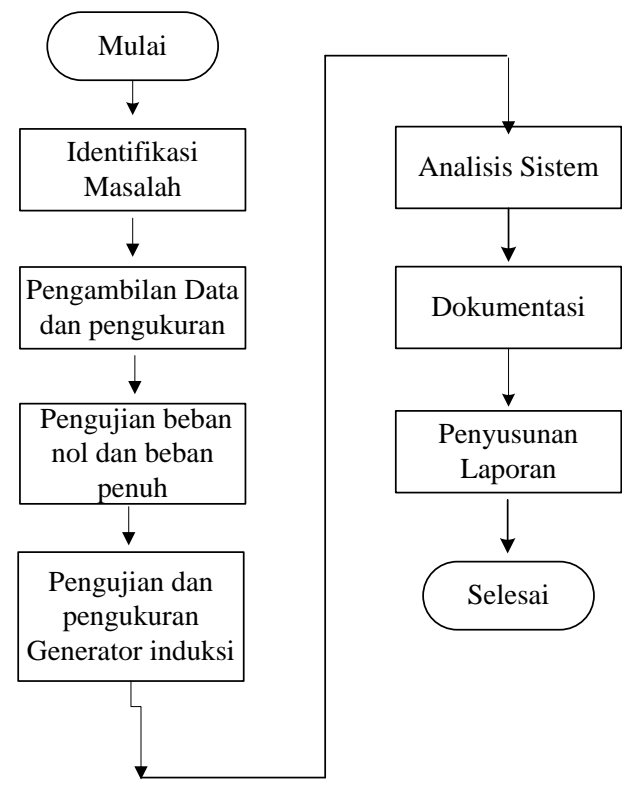

Gambar 1. Diagram alur jalan penelitian

\section{HASIL DAN PEMBAHASAN}

\subsection{Pengujian Motor Induksi Tanpa Beban}

Pengujian motor induksi tiga fasa pada beban kosong atau tanpa beban bertujuan untuk mendapatkan parameter impedansi pada belitan penguatan yaitu nilai Xo dan Ro. Dengan mengetahui parameter ini kerugian daya pada belitan penguatan medan dapat diketahui besarnya.

Tabel 1. Hasil Pengujian dan Pengukuran Motor Induksi Tanpa Beban

\begin{tabular}{|c|c|c|c|c|c|c|c|c|c|c|}
\hline \multirow{3}{*}{ No } & \multirow{3}{*}{$\begin{array}{c}\text { Jenis } \\
\text { Pengujian } \\
\text { motor induksi }\end{array}$} & \multicolumn{9}{|c|}{ Besaran Listrik Terukur } \\
\hline & & \multirow{2}{*}{$\begin{array}{r}\text { Daya } \\
\text { aktif }\end{array}$} & \multirow{2}{*}{$\begin{array}{c}\begin{array}{c}\text { Arus } \\
\text { fasa } \\
\mathbf{I}_{\mathrm{F}}\end{array} \\
\text { amper }\end{array}$} & \multirow{2}{*}{$\begin{array}{c}\text { Tega } \\
\text { ngan } \\
\mathrm{V}_{\mathrm{L}-\mathrm{L}} \\
\text { volt } \\
\end{array}$} & \multicolumn{3}{|c|}{$\begin{array}{c}\text { Resistansi } \\
\text { kumparan stator } \\
\text { (ohm) }\end{array}$} & \multirow{2}{*}{$\begin{array}{c}\begin{array}{c}\text { Kecep } \\
\text { atan } \\
\text { stator }\end{array} \\
\text { rpm }\end{array}$} & \multirow{2}{*}{$\begin{array}{c}\begin{array}{c}\text { Kecepat } \\
\text { an } \\
\text { rotor }\end{array} \\
\text { rpm }\end{array}$} & \multirow{2}{*}{$\begin{array}{l}\text { Suhu belitan stator } \\
\text { akhir } \\
\text { Suhu awal }=25^{\circ} \mathrm{C} \\
{ }^{\circ} \mathrm{C}\end{array}$} \\
\hline & & & & & $\mathbf{X}$ & $\mathbf{Y}$ & $\mathbf{Z}$ & & & \\
\hline 1 & $\begin{array}{l}\text { Pengukuran } \\
\text { resistansi }\end{array}$ & - & - & - & 5,1 & 5,1 & 5,1 & - & - & - \\
\hline & Jangkar & & & & & & & & & \\
\hline \multirow{5}{*}{2} & & 1030 & 2,31 & 354 & - & - & - & 1500 & 1096 & 25,0 \\
\hline & Pengujian & 1190 & 2,34 & 374 & - & - & - & 1500 & 1170 & 25,0 \\
\hline & beban & 1260 & 2,41 & 387 & - & - & - & 1500 & 1236 & 25,0 \\
\hline & kosong & 1400 & 2,46 & 390 & - & - & - & 1500 & 1298 & 25,1 \\
\hline & & 1880 & 2,57 & 430 & - & - & - & 1500 & 1498 & 25,1 \\
\hline
\end{tabular}




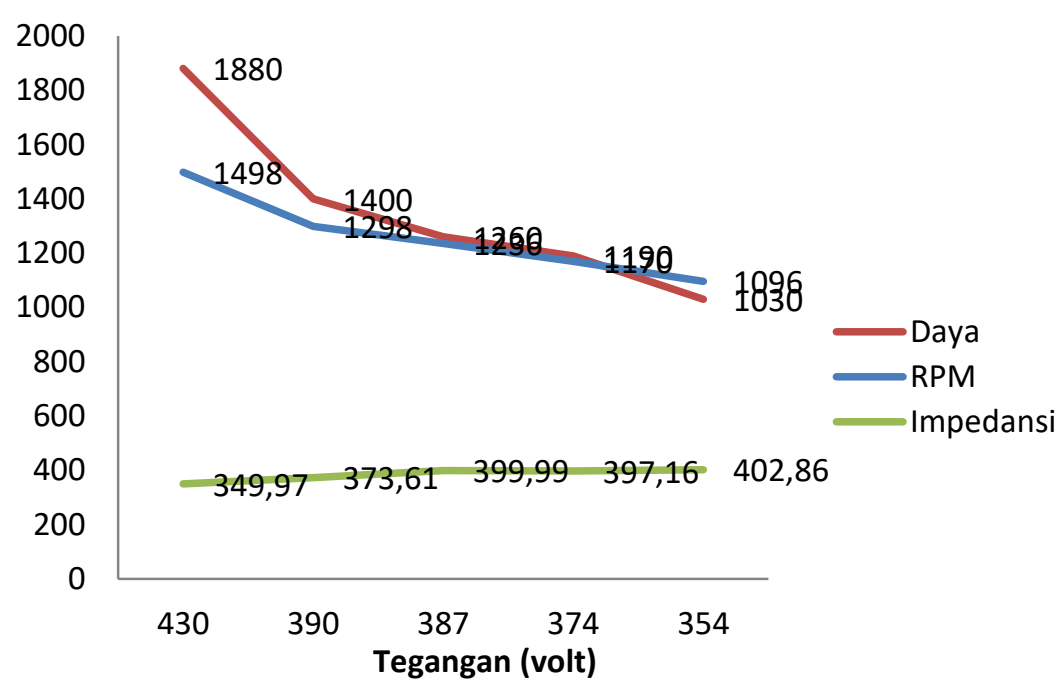

Gambar 2. Hubungan daya aktif, kecepatan rotor, impedansi dengan tegangan uji saat pengujian motor induksi tanpa beban

Pada Gambar 2 memperlihatkan bahwa daya aktif antara 1096 s/d 1880 watt dan kecepatan rotor 1030 s.d 1498 rpm besarnya berbanding lurus dengan tegangan uji dan sebaliknya impedansi motor antara 349,97 s/d 402,86 besarnya berbanding terbalik dengan tegangan uji.

\subsection{Pengujian Motor Induksi Berbeban dan Berbeban penuh}

Pengujian motor induksi tiga fasa berbeban penuh atau blok tes beban bertujuan untuk mendapatkan parameter impedansi belitan rotor yaitu nilai X2 dan R2. Dengan mengetahui parameter ini kerugian daya pada belitan rotor dapat diketahui besarnya.

Tabel 2. Hasil Pengujian Motor Induksi Berbeban dan Beban penuh

\begin{tabular}{|c|c|c|c|c|c|c|c|}
\hline \multirow{3}{*}{ No } & \multirow[b]{2}{*}{$\begin{array}{l}\text { Jenis Pengujian } \\
\text { motor induksi }\end{array}$} & \multicolumn{6}{|c|}{ Besaran Listrik Terukur } \\
\hline & & $\begin{array}{l}\text { Daya } \\
\text { aktif }\end{array}$ & $\begin{array}{c}\text { Arus } \\
\text { fasa } \\
\mathbf{I}_{\mathrm{F}}\end{array}$ & $\begin{array}{c}\text { Tegangan } \\
\mathbf{V}_{\mathrm{L}-\mathrm{L}}\end{array}$ & $\begin{array}{l}\text { Kecepatan } \\
\text { stator }\end{array}$ & $\begin{array}{l}\text { Kecepatan } \\
\text { rotor }\end{array}$ & $\begin{array}{c}\text { Suhu belitan stator } \\
\text { akhir } \\
\text { Suhu awal }=25^{\circ} \mathrm{C}\end{array}$ \\
\hline & & watt & amper & volt & rpm & rpm & ${ }^{\circ} \mathrm{C}$ \\
\hline \multirow{5}{*}{1} & \multirow{5}{*}{$\begin{array}{l}\text { Pengujian } \\
\text { berbeban }\end{array}$} & 1692 & 4,75 & 374 & 1500 & 1242 & 25,4 \\
\hline & & 1810 & 4,97 & 379 & 1500 & 1243 & 25,9 \\
\hline & & 1980 & 5,32 & 385 & 1500 & 1244 & 26,2 \\
\hline & & 2125 & 5,84 & 390 & 1500 & 1246 & 26,3 \\
\hline & & 2246 & 6,23 & 400 & 1500 & 1247 & 26.4 \\
\hline \multirow{5}{*}{2} & \multirow{5}{*}{$\begin{array}{c}\text { Pengujian } \\
\text { beban penuh }\end{array}$} & 415 & 5,69 & 85 & 0 & 0 & 26,6 \\
\hline & & 780 & 7,76 & 95 & 0 & 0 & 26,7 \\
\hline & & 840 & 8,79 & 105 & 0 & 0 & 26,8 \\
\hline & & 970 & 9,69 & 115 & 0 & 0 & 26,9 \\
\hline & & 1020 & 10,98 & 130 & 0 & 0 & 26,9 \\
\hline
\end{tabular}




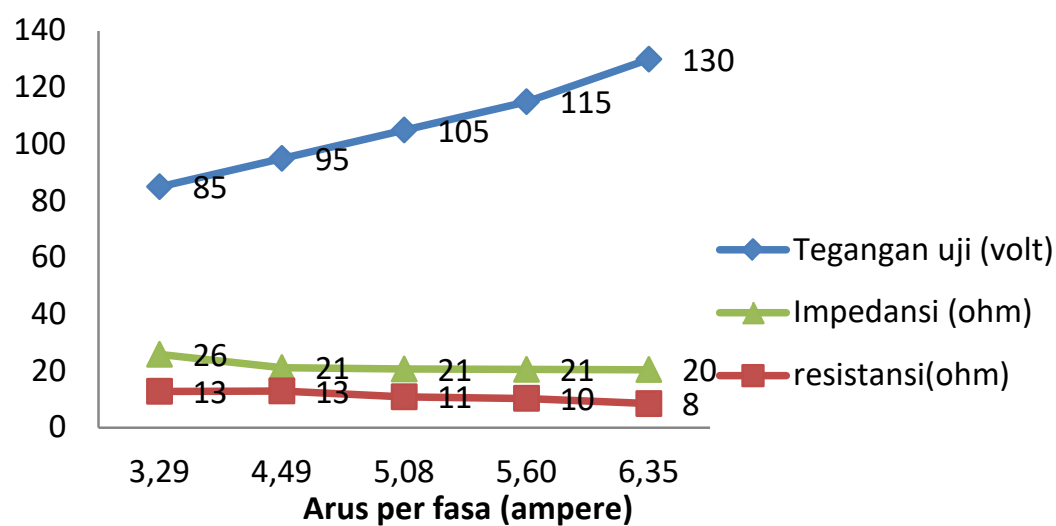

Gambar 3. Hubungan tegangan, impedansi dengan arus uji pada pengujian motor induksi beban penuh

Pada Gambar 3. memperlihatkan besarnya tegangan uji dari 85 volt s.d 130 volt menyebabkan perubahan nilai impedansi dan resistansi yaitu dari 26 ohm menjadi 20 ohm pada arus uji antara 3,29 ampere sampai dengan 6,35 ampere.

Dari Tabel 1 dan Tabel 2 maka parameter motor induksi tiga fasa rotor sangkar dapat diketahui nilainya seperti Tabel 3.

Tabel 3. Data parameter motor induksi motor induksi tiga fasa

\begin{tabular}{|c|c|c|c|c|c|c|c|c|}
\hline \multirow{2}{*}{ No } & \multicolumn{8}{|c|}{ Parameter motor induksi tiga fasa } \\
\hline & $\begin{array}{c}\text { Ro } \\
\text { (ohm) }\end{array}$ & $\begin{array}{c}\text { Xo } \\
\text { (ohm) }\end{array}$ & $\begin{array}{c}\mathrm{R}_{\mathrm{E}} \\
\text { (ohm) }\end{array}$ & $\begin{array}{c}\mathrm{X}_{\mathrm{E}} \\
\text { (ohm) }\end{array}$ & $\begin{array}{c}\mathrm{R}_{\text {sta }} \\
\text { (ohm) }\end{array}$ & $\begin{array}{c}\mathrm{R}_{\mathrm{rot}} \\
\text { (ohm) }\end{array}$ & $\begin{array}{c}\mathrm{X}_{\text {sta }} \\
\text { (ohm) }\end{array}$ & $\begin{array}{c}\mathrm{X}_{\text {rot }} \\
\text { (ohm) }\end{array}$ \\
\hline 1 & 295,05 & 188,25 & 12,79 & 22,5 & 5,1 & 7,69 & 11,25 & 11,25 \\
\hline 2 & 325,93 & 182,47 & 12,92 & 16,8 & 5,1 & 7,82 & 8,4 & 8,4 \\
\hline 3 & 356,59 & 180,40 & 10,85 & 17,6 & 5,1 & 5,75 & 8,8 & 8,8 \\
\hline 4 & 352,63 & 181,99 & 10,31 & 17,8 & 5,1 & 5,21 & 8,9 & 8,9 \\
\hline 5 & 365,00 & 170,54 & 8,44 & 18,7 & 5,1 & 3,34 & 9,35 & 9,35 \\
\hline
\end{tabular}

Dengan menggunakan rangkaian ekuivalen motor induksi dan Tabel 3 dapat diperoleh beberapa besaran listrik seperti daya input motor induksi, kerugian daya motor induksi saat tidak berbeban, kerugian daya pada belitan stator dan rotor, serta efisiensi dan torsi motor induksi berdasarkan persamaan berikut (8):

a. Impedansi total rangkaian ekuivalen $\left(\mathrm{Z}_{\mathrm{T}}\right)$

$$
\begin{aligned}
& Z_{T}=Z_{1}+\frac{Z_{o} \cdot Z_{2}+R_{2}^{\prime}\left[\frac{1-s}{s}\right]}{Z_{o}+Z_{2}+R_{2}^{\prime}\left[\frac{1-s}{s}\right]}=(5,1+J 11,23)+\frac{(295,05+J 188,25) \cdot\left(\left[\frac{7,69}{0,17}\right]+j 11,23\right)+7,69 \cdot\left[\frac{1-0,17}{0,17}\right]}{(295,05+j 188,25)+(45+j 11,23)+37,5} \\
& 71,9+J 25,83=76,4 \angle 19,7^{\circ} \text { Ohm }
\end{aligned}
$$

b. Arus yang mengalir pada kumparan stator $\left(\mathrm{I}_{1}\right)$

$$
I_{1}=\frac{V_{1}}{Z_{T}}=\frac{375 \angle 0^{\circ}}{76,4 \angle 19,7^{\circ}}=4,91 \angle-19,7^{\circ} \text { ampere }
$$

c. Tegangan kumparan magnet $\left(\mathrm{V}_{\mathrm{AB}}\right)$

d. Arus magnetisasi ( $\left.\mathrm{I}^{\phi}\right)$

$$
V_{A B}=V_{1}-I_{1} * Z_{1}=375 \angle 0^{\circ}-4,91 \angle-19,7^{\circ} * 12,33 \angle 65,6^{\circ}=332 \angle-7,5^{\circ} \quad \text { Volt }
$$

$$
I_{\phi}=\frac{V_{A B}}{Z_{o}}=\frac{332 \angle-7,5^{\circ}}{349,97 \angle 32,5^{\circ}}=0,95 \angle-40^{\circ} \text { ampere }
$$

e. $\operatorname{Arus} \operatorname{Rotor}\left(\mathrm{I}_{2}\right)$

$$
I_{2}=I_{1}-I_{\varnothing}=4,91 \angle-19,7^{\circ}-0,95 \angle 0,95^{\circ}=4,02 \angle-14,8^{\circ} \text { ampere }
$$

f. Rugi daya pada kumparan stator $\left(\mathrm{P}_{\mathrm{R} 1}\right)$

$$
P_{R 1}=3 \cdot I_{1}^{2} \cdot R_{1}=3 \cdot 4,91^{2} \cdot 5,1=369 \mathrm{watt}
$$

g. Daya masuk rotor $\left(\mathrm{P}_{\mathrm{G}}\right)$

$$
P_{G}=3 \cdot I_{2}^{2} \cdot \frac{R_{2}}{S}=3 \cdot 4,02^{2} \cdot \frac{7,69}{0,17}=2197 \mathrm{watt}
$$

h. Daya input motor $\left(\mathrm{P}_{\mathrm{IN}}\right)$

$$
P_{I N}=P_{R 1}+P_{G}=369+2197=2565 \mathrm{watt}
$$

i. $\quad$ Rugi daya pada kumparan rotor $\left(\mathrm{P}_{\mathrm{R} 2}\right)$ 


$$
P_{R 2}=s \cdot P_{G}=0,17.2197=373,5 \mathrm{watt}
$$

j. $\quad$ Daya mekanik rotor $\left(\mathrm{P}_{\mathrm{M}}\right)$

$$
P_{M}=3 \cdot I_{2}^{2} \cdot R_{2}\left[\frac{1-s}{s}\right]=3 \cdot 4,02^{2} \cdot 7,69\left[\frac{1-0,17}{0,17}\right]=1823 \text { watt }
$$

k. Efisiensi motor induksi $(\eta)$

$$
\eta=\frac{P_{M}}{P_{I N}}=\frac{1823}{2565}=71,1 \%
$$

l. Torsi Motor Induksi ( Tm)

$$
T_{m}=\frac{9,55 \cdot P_{M}}{N_{r}}=\frac{9,55.1823}{1245}=14 \mathrm{Nm}
$$

Dari besaran motor induksi di atas maka besarnya daya input motor dan daya mekanik dapat diketahui serta besarnya torsi dan efisiensi.

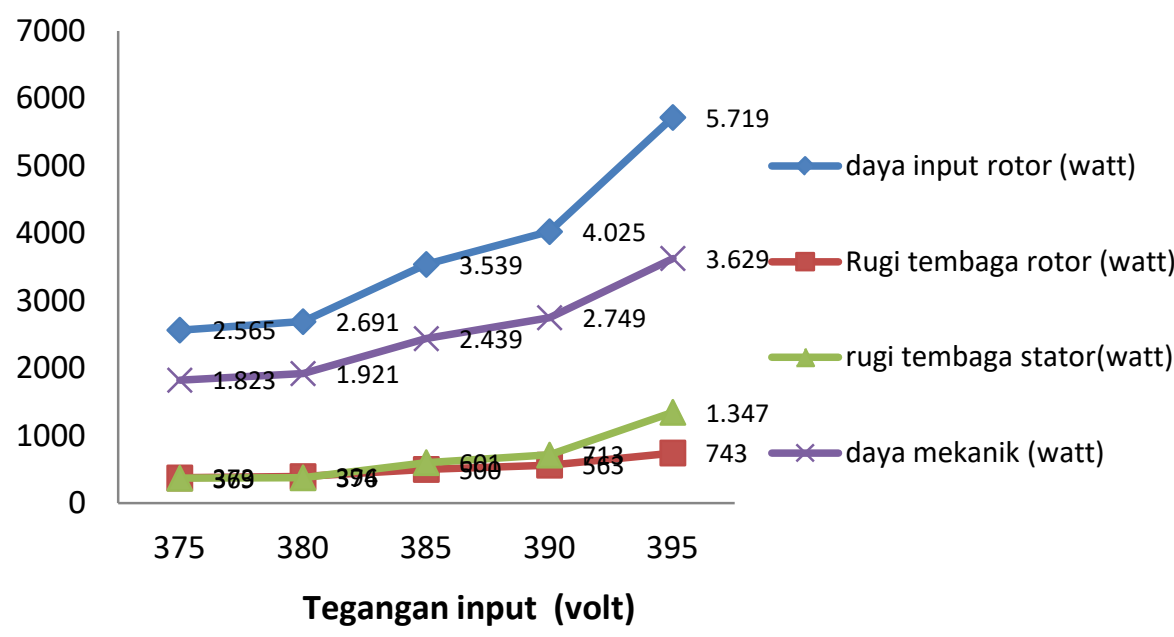

Gambar 4. Hubungan daya input rotor, rugi daya,daya mekanik dengan tegangan input

Pada Gambar 4, memperlihatkan perbandingan daya input rotor dengan besarnya kerugian pada kumparan stator dan rotor yaitu pada tegangan kerja 375 volt, daya input 2565 watt terjadi kerugian pada kumparan stator dan rotor sebesar 743 watt dan daya mekanik yang dikeluarkan oleh motor induksi adalah sebesar 1823 watt dan hubungan antara kerugian daya pada motor berbanding lurus dengan tegangan kerja yang diterapkan.

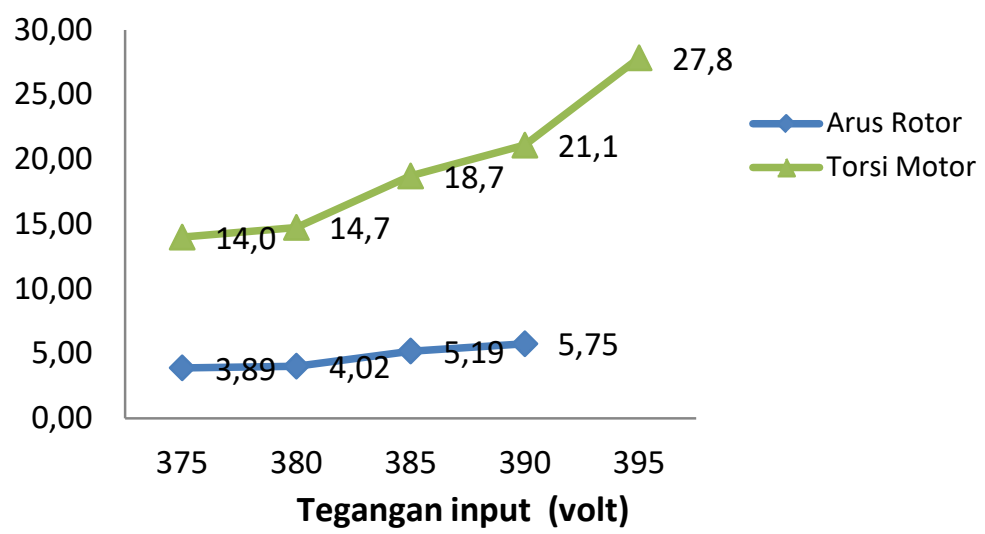

Gambar 5. Hubungan arus stator dengan torsi yang dihasilkan

Dari hasil perhitungan dan Gambar 5 arus listrik yang diserap oleh belitan stator pada besaran 3,89 ampere menghasilkan torsi sebesar $14 \mathrm{Nm}$, dan pada gambar terlihat hubungan antara arus stator dan torsi yang dihasilkan adalah linier. 


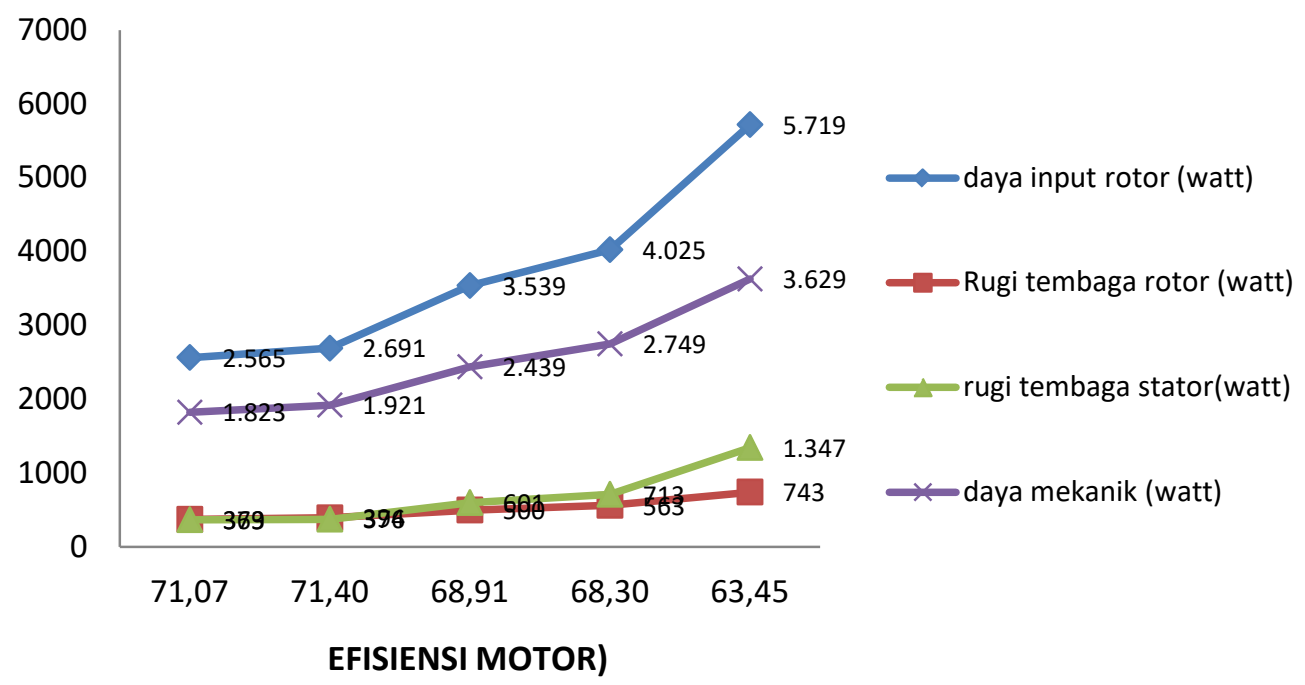

Gambar 6. Hubungan Efiseinsi motor dengan kerugian daya pada stator dan rotor

Pada Gambar 6 dijelaskan bahwa besarnya efisiensi motor ditentukan oleh daya input stator dan daya mekanik yang dihasilkan rotor serta kerugian daya pada belitan rotor dan stator. Besarnya efisiensi motor turun akibat adanya kenaikan beban dan kerugian daya pada belitan rotor dan stator yang cenderung naik akibat arus pada stator dan rotor juga naik.

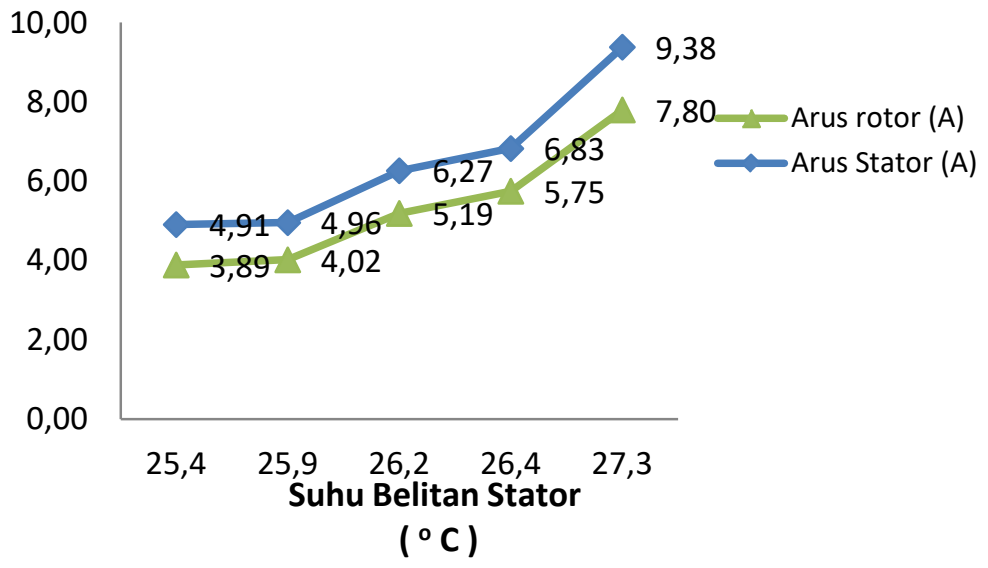

Gambar 7. Hubungan Suhu belitan stator dengan arus rotor dan arus stator

Pada Gambar 7 dijelaskan bahwa temperatur belitan stator mengalami kenaikan suhu akibat adanya kenaikan beban. Kenaikan beban mengakibatkan kenaikan arus pada belitan stator, kenaikan arus pada belitan stator mengakibatkan suhu pada belitan stator.

\section{KESIMPULAN}

Penelitian ini menggunakan motor induksi tiga fase rotor sangkar yang mempunyai kecepatan sinkron 1420 rpm dengan daya listrik $4 \mathrm{HP}$, tegangan kerja 380 volt pada frekuensi $50 \mathrm{~Hz}$. Setelah motor induksi di uji dengan beban penuh, berbeban normal danuji tanpa beban, maka di dapatkan besaran motor induksi seperti daya input motor, daya mekanik, torsi motor dan efisieinsi motor, misalnya pada pengujian motor induksi berbeban pada tegangan kerja 375 volt di dapatkan daya input 2565 watt dengan kerugian pada kumparan stator dan rotor sebesar 743 watt, daya mekanik yang dikeluarkan oleh motor induksi adalah sebesar 1823 watt, torsi yang dihasilkan rotor sebesar $14 \mathrm{Nm}$ dan efisiensi motor sebesar 71,07 \%.

\section{UCAPAN TERIMAKASIH}

Ucapan terima kasih kami sampaikan kepada Lembaga Penelitian dan Pengabdian pada Masyarakat (LPPM) Universitas Muhammadiyah Purwokerto yang telah membiayai penelitian ini. 


\section{DAFTAR PUSTAKA}

[1]. Andrade CTC, Pontes RST. Three-Phase Induction Motors Energy Efficiency Standards - - A Case Study -. 2001;

[2]. El-ibiary Y. An Accurate Low-Cost Method for Determining Electric Motors ' Efficiency for the Purpose of Plant Energy Management. 2003;39(4):1205-10.

[3]. Mantilla SCERLF. How the efficiency of induction motor is measured ? 2008;1(6):530-4.

[4]. Suyamto. Analisis daya dan torsi pada motor induksi. In: Seminar Nasional V, SDM Teknologi Nuklir, BATAN. Yogyakarta; 2009. p. 205-12.

[5]. Ghazali RA. Metode Perhitungan Efisiensi Motor Induksi Yang Sedang Beroperasi. Universitas Indonesia; 2011.

[6]. Antonov, Oktariani Y. Studi Pengaruh Torsi Beban Terhadap Kinerja Motor Induksi Tiga Fase. J Tek Elektro ITP. 2016;5(1):9-15.

[7]. Susanto E. Pengujian Unjuk Kerja Dan Pengukuran Parameter Motor Induksi Satu Fasa [Internet]. Universitas Muhammadiyah Surakarta; 2017. Available from: http://puslit2.petra.ac.id/ejournal/index.php/elk/article/view/17356

[8]. Zuhal. Dasar Tenaga Listrik. Institut Teknologi Bandung (ITB). Bandung. 1991 